\title{
A Bibliometric Description of Lignin Applicability for the Removal of Chemical Pollutants in Effluents
}

\author{
Maria Nazaré Oliveira Teles • \\ Brenda Lohanny Passos Santos • Daniel Pereira Silva • \\ José António Teixeira • Denise Santos Ruzene
}

Received: 12 February 2020 / Accepted: 4 June 2020

(C) Springer Nature Switzerland AG 2020

\begin{abstract}
Several industrial sectors produce tons of effluents daily containing a high amount of hazardous chemical pollutants that pose a major threat to the environment and human health. Current wastewater treatment methods, such as flocculation and activated carbon adsorption, have drawbacks linked to high material cost and too much energy consumption. Thus, the search for renewable, biodegradable, and efficient materials has been the object of research aimed at replacing the conventional materials used to cheapen processes and reduce environmental impacts. Lignin stands out in this context as it has low cost and high availability. Therefore, several scientific researches were developed to harness the potential of lignin, especially as adsorbent, for the removal of chemical agents from effluents. This paper presents a bibliometric review performed on the
\end{abstract}

M. N. O. Teles - B. L. P. Santos - D. P. Silva - D. S. Ruzene Center of Exact Sciences and Technology, Federal University of Sergipe, São Cristóvão, Sergipe 49100-000, Brazil

B. L. P. Santos · D. P. Silva · D. S. Ruzene

Northeastern Biotechnology Network-RENORBIO/SE, Federal University of Sergipe, São Cristóvão, Sergipe 49100-000, Brazil

\section{J. A. Teixeira}

Centre of Biological Engineering, University of Minho,

4710-057 Braga, Portugal

\section{S. Ruzene $(\bowtie)$}

Department of Chemical Engineering, Federal University of Sergipe, Rodovia Marechal Rondon, s/n, Jardim Rosa Elze, São Cristóvão, Sergipe 49100-000, Brazil

e-mail: ruzeneds@hotmail.com
Scopus database, showing the evolution of studies related to the applicability of lignin in the removal of chemical pollutants in waters over the last five years. Data regarding annual publications, languages, journals, countries, institutions, keywords, and subjects were analyzed. The realized screening selected 130 articles that met the previously defined criteria. Results indicated a strong collaboration between countries and China's substantial contribution to the documents. The analysis also has shown that lignin is mainly used as adsorbent material, sorbent, flocculant agent, and hydrogel and presents important results and information for future researchers on this topic.

Keywords Lignin - Chemical pollutants · Effluents · Bibliometric analysis

\section{Introduction}

Water pollution is one of the most severe environmental problems due to changes in the chemical, physical, and biological characteristics of water. It causes severe damage to aquatic species and makes water unfit for human consumption (Zhang et al. 2011). Industrial discharges containing dyes, pesticides, fertilizers, heavy metals, and their compounds are released excessively in water bodies due to the activity of various industries, such as dyeing, textile, printing, mining, paper and plastic, and cosmetics (Aniagor and Menkiti 2018; Demcak et al. 2017; Guo et al. 2018a). Such effluents are powerful sources of pollution since they are not biodegradable by organisms 
generally used in biological treatments and are accumulative, reaching lethal concentrations for fish and invertebrates. Furthermore, through bioaccumulation along the food chain, carcinogenic and mutagenic effects can be observed in humans (Almeida et al. 2004). The high toxicity of these effluents can be attributed to the presence of recalcitrant compounds that are generally not compatible with most existing biological treatments. This class includes pesticides, dyes, and heavy metals (Aniagor and Menkiti 2018; Yao et al. 2009).

Conventional treatments, such as precipitation, ion exchange, microbial degradation, and adsorption with activated charcoal, present some limitations regarding high operational costs and difficulty in meeting regulatory requirements (Domínguez-Robles et al. 2018; Ge et al. 2014a; Guo et al. 2008; Pereira and Ebecken 2009). For this reason, several studies have been carried out to use efficient, biodegradable, and low-cost materials to remove these pollutants. Lignins from lignocellulosic residues are a powerful alternative, as they have the phenol, carboxyl, and hydroxyl functional groups that can be linked to chemical pollutant structures, promoting the removal of these compounds from industrial effluents (Ge et al. 2014a; Guo et al. 2008). Moreover, the polycyclic structure of lignin has negatively charged functional groups that act as chelating agents sequestering heavy metals in effluents (Nasrullah et al. 2016).

Lignin is an insoluble aromatic polymer that confers mechanical resistance to the plant wall and protection against the action of microorganisms, besides acting on the transportation of water, nutrients, and metabolic compounds (Zhao 2016; Bhatia et al. 2020). This polymer can be found in agricultural by-products, such as sugarcane bagasse and corn straw, as well as in a byproduct known as black liquor, obtained in the separation phase of wood pulp on paper production. Given its abundance, as these sectors generate large amounts of effluents daily, several studies propose using lignin as a precursor material to obtain biomaterials. The purpose of these biomaterials is to remove industrial wastewater pollutants, replacing the materials used initially to treat aqueous waste, improving efficiency, lowering both implementation and process costs. These materials have several advantages, such as low cost, no emission of toxic chemicals at the end of the process, and they allow the selective separation of the main components, besides being a renewable and abundance source (Halysh et al. 2018; Michelin et al. 2012; Ogunsile and Bamgboye 2017; Wang et al. 2017).
Due to the large number of studies related to the use of lignin to remove chemical pollutants in industrial effluents, a bibliometric analysis is proposed to portray global research trends within this scope. Bibliometric methods use various statistical techniques of bibliographic counting to evaluate and quantify the development of the literature concerning a particular issue (Tsay 2008; Abejón et al. 2018; Mao et al. 2018). It employs statistical indices and uses quantitative analysis to obtain information about publication standards for specific categories, such as institutions, individuals, and countries to evaluate their scientific outputs (Abejón 2018; Zyoud et al. 2017). Therefore, this paper presents a bibliometric and network review in the Scopus multidisciplinary database from 2014 to 2019, addressing the recent scenario of scientific research on the applicability of lignin for the removal of chemical pollutants from effluents, as an efficient and sustainable alternative to conventional treatments.

\section{Methodology}

\subsection{Search and Search Strategy}

The online search was performed on the Scopus database and was completed on January 4, 2019. The Scopus was chosen because it has the most extensive peer-reviewed literature, with 24,600 active titles and 5000 publishers, providing a high range of abstract and citation for bibliometric analysis. The following keywords were used with Boolean operators as a search strategy: TITLEABS-KEY (lignin AND (metal* OR dye*) AND (absorbent OR adsorbent OR removal OR sorbent OR biosorbent OR biosorvent OR "bio sorvent")). This set was selected for scientific articles only and initially resulted in 848 documents. However, this paper aims are to analyze the scientific production of articles published between 2014 and 2019. The search was restricted to this period, generating 430 publications that were evaluated by titles, abstracts, and in full. Documents that did not correspond to the proposed theme were discarded, including the works related to the full use of lignocellulosic materials for the removal of pollutants and the use of lignin peroxidase enzyme for wastewater treatment. Other publications were also discarded, such as the ones regarding the use of lignin as a dye dispersing agent (Qiu et al. 2018) and delignification of lignocellulosic materials or removal of effluent lignin (Ennaert et al. 2016; Shuhailath et al. 2016; Yadav and Garg 2016). Inclusion and exclusion 
criteria were previously defined before the evaluation. All languages were considered in the analysis.

This filtering process excluded 300 publications and resulted in 130 articles, which were analyzed and categorized according to their different typologies. Hence, a preliminary bibliometric analysis was performed in the Scopus database itself.

\subsection{Bibliometric Maps}

VOSviewer software was used in later steps for statistical analysis and material networks. The variables investigated were year of publication, journals, country, authors, knowledge area, institutions, keywords, subject type, and citation analysis. Bibliometric indicators, such as CiteScore, h-index, and Journal Citation Reports (JCR), and SCImago Journal Rank (SJR) impact factors for 2017 were used for classification purposes.

VOSviewer is a software used for the construction and visualization of bibliometric maps based on network data using VOS mapping and VOS grouping techniques. It can be used to study maps that emphasize information on publications, bibliography, citations, author, and keywords (Md Khudzari et al. 2018; Ruas and Pereira 2014).

\section{Results and Discussion}

\subsection{Publishing Trends and Documents Language}

The trend of annual publications on the applicability of lignin in the treatment of effluents containing chemical pollutants is shown in Fig. 1. The results demonstrate that the annual publications had a small decrease between the first three years, but between 2016 and 2018, there was a sharp increase in the number of documents. In 2019, although data collection was carried out at the beginning of the year, a considerable amount of work was found describing the use of lignin for this purpose. It is possible to assume that there is a progressive growth trend in the number of researches focused on this theme.

The use of renewable raw materials, such as lignin, for the production of pollutant removers' materials is on the rise. It is motivated by the concern for the environment, which stimulates the development of studies aimed at finding alternatives that minimize the environmental impacts generated by the various industrial activities.
Among the languages present in the publications, English was the most used, totaling $90 \%$ of the articles. Three other languages were found, which are as follows: Chinese $(8.46 \%)$ with the second-highest percentage, and French and Spanish, with $0.77 \%$ each. These results corroborate with those listed in the literature, as in the bibliometric study conducted by Abejón (2018), which demonstrated the predominance of the English language in the areas of environmental and chemical engineering.

\subsection{Areas of Activity}

Seventeen academic areas were found with studies that contributed to the development of research on the proposed theme. Figure 2 shows the percentage of contribution in each area.

As observed in Fig. 2, the outstanding academic areas were chemical engineering (20.7\% of the total), followed by chemistry (20.0\%), and environmental science $(16.8 \%)$. Areas such as materials science, engineering, physics and astronomy, biochemistry, genetics and molecular biology, energy, agronomy, and life sciences have also contributed significantly, with most work aimed at developing research on the application of lignin for pollutant removal. Other areas represented $5.0 \%$ of the total. These results show the multidisciplinary collaboration between different areas about the thematic approached: lignin applicability for the removal of chemical pollutants in effluents.

\subsection{Distribution of Publications by Country and by Institution}

Table 1 groups the top ten most productive countries in collaboration for growing research on the use of lignin to remove pollutants from water. These countries are responsible for $75.70 \%$ of publications, and $61.26 \%$ of this total is distributed among the first four ones. More specifically, China has the largest number of publications, followed by the United States. Such numbers may be justified by the high agricultural activity and the pulp and paper production of these countries. The report released by the Food and Agriculture Organization of the United Nations (FAO) estimates that for the 2016-2022 period, the leading world pulp and paper producing countries will be China, United States, Germany, and Canada (FAO 2019). This scenario indicates that there is a large production of biomass residues that can be used for lignin extraction, explaining the high development of research for the utilization of this polymer in these countries. 
Fig. 1 Annual trend of publications in original articles of 2014 to early 2019 in Scopus, following the thematic of lignin applicability for the removal of chemical pollutants in effluents

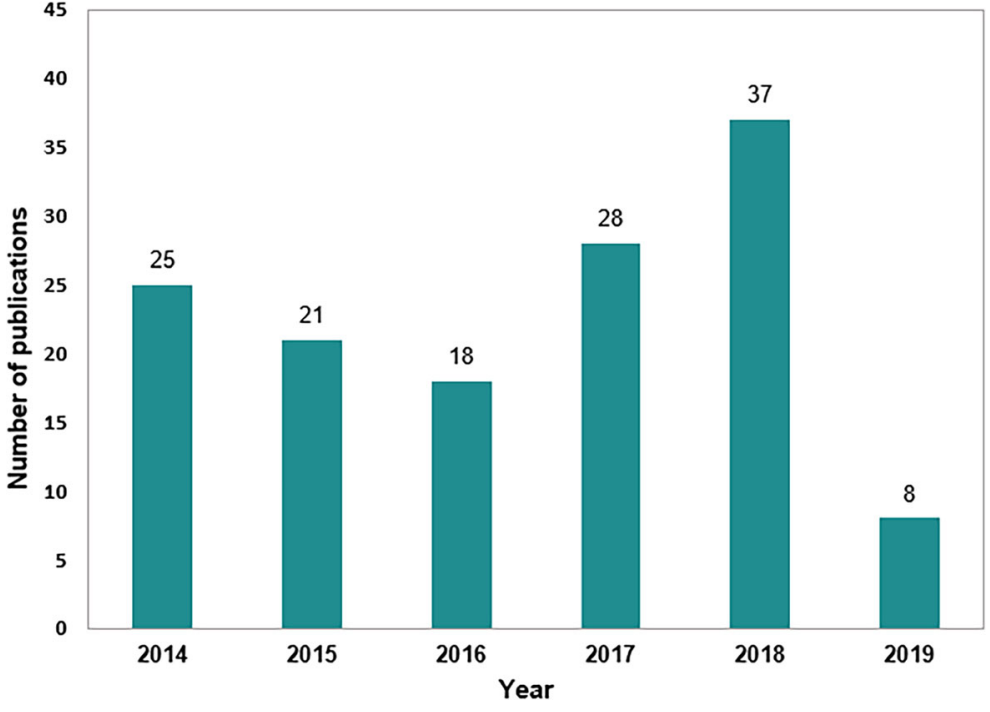

The geographical distribution of articles from all 30 countries involved is presented in the choropleth map of Fig. 3. The most intense coloration indicates the countries that have the most significant number of scientific articles. It is known that China has the highest density of publications, as well as the United States, confirming the data presented in Table 1.

Regarding the sharing of published articles, Fig. 4 shows a detailed map with the cross-country collaboration network. The number of documents in collaboration determines the relationship between countries. Thus, the size of the nodes is proportional to the number of articles published by each country, and the thickness of each line represents the strength of cooperation between them.

The leading countries in the number of publications are also among the most active, with the highest amount of collaborations coming from United Kingdom (8

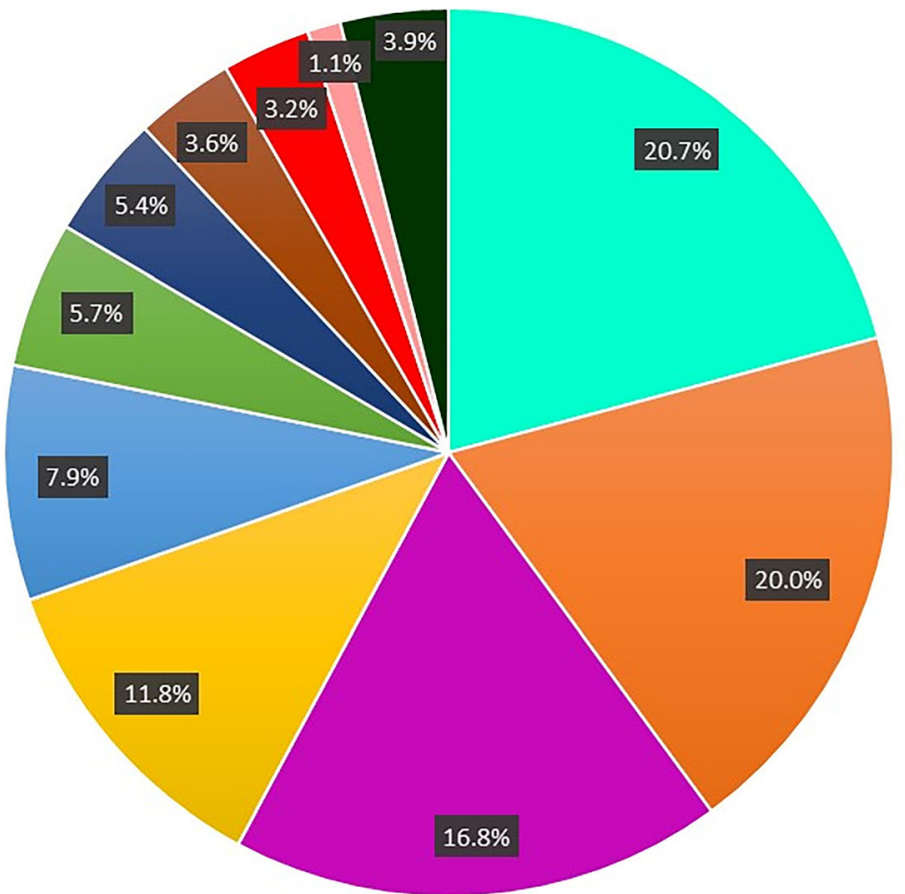

- Chemical Engineering

- Chemistry

- Environmental Science

Materials Science

घngineering

- Physics and Astronomy

- Biochemistry, Genetics and Molecular Biology

घnergy

- Agricultural and Biological Sciences

$\square$ Computer Science

Fig. 2 Multidisciplinary collaboration represented by the top 10 academic areas on lignin applicability for removal of chemical pollutants 
Table 1 Publications of the 10 most productive countries

\begin{tabular}{llll}
\hline \multicolumn{2}{l}{ Country } & Number of publications & Percentage (\%) \\
\hline 1 & China & 76 & 43.93 \\
2 & United States & 13 & 7.51 \\
3 & Poland & 9 & 5.20 \\
4 & Canada & 8 & 4.62 \\
5 & India & 5 & 2.89 \\
6 & Germany & 4 & 2.31 \\
7 & Will & 4 & 2.31 \\
8 & Nigeria & 4 & 2.31 \\
9 & South Korea & 4 & 2.31 \\
10 & United Kingdom & 4 & 2.31 \\
\hline
\end{tabular}

countries), followed by the United States (6 countries) and Sweden (5 countries). Despite its many collaborative articles, in terms of variety, China has collaborations with only four countries, the most significant of which is with the United States, as can be seen from the higher line thickness in Fig. 4. On the other hand, five countries did not share publications, which are as follows: Colombia, Egypt, Taiwan, Turkey, and Portugal.

A total of 160 institutions from the 30 countries analyzed published the selected articles. Of this amount, $76.9 \%$ had only one document. The ten most productive institutions are listed in Table 2. Seven of the most active ones are in China, ratifying the results obtained previously. Poland has two institutions, followed by Canada, with only one. Although the United States is the second country in number of publications, its institutions are not among the most productive because they publish one or two papers each, suggesting that scientific production is distributed.

The analysis of the collaborative research carried out by the different countries shows their concern and interest in the development of research aiming at the use of lignin as a sustainable and renewable alternative for the removal of chemical pollutants from effluents.

\subsection{Highly Cited Papers}

To provide information on which topics have the most attention by researchers and what are the leading chemical pollutants that are usually removed by lignin, a survey of the most cited articles between the years 2014 and early 2019 was conducted. Table 3 lists the top 10 highly cited papers among the 130 ones previously selected. According to Scopus Metrics, all citations were included.

Three papers listed in the ranking were published in Chemical Engineering Journal, two in Journal of Hazardous Materials, and two more in ACS Applied Materials and Interface. Coincidentally, all of them

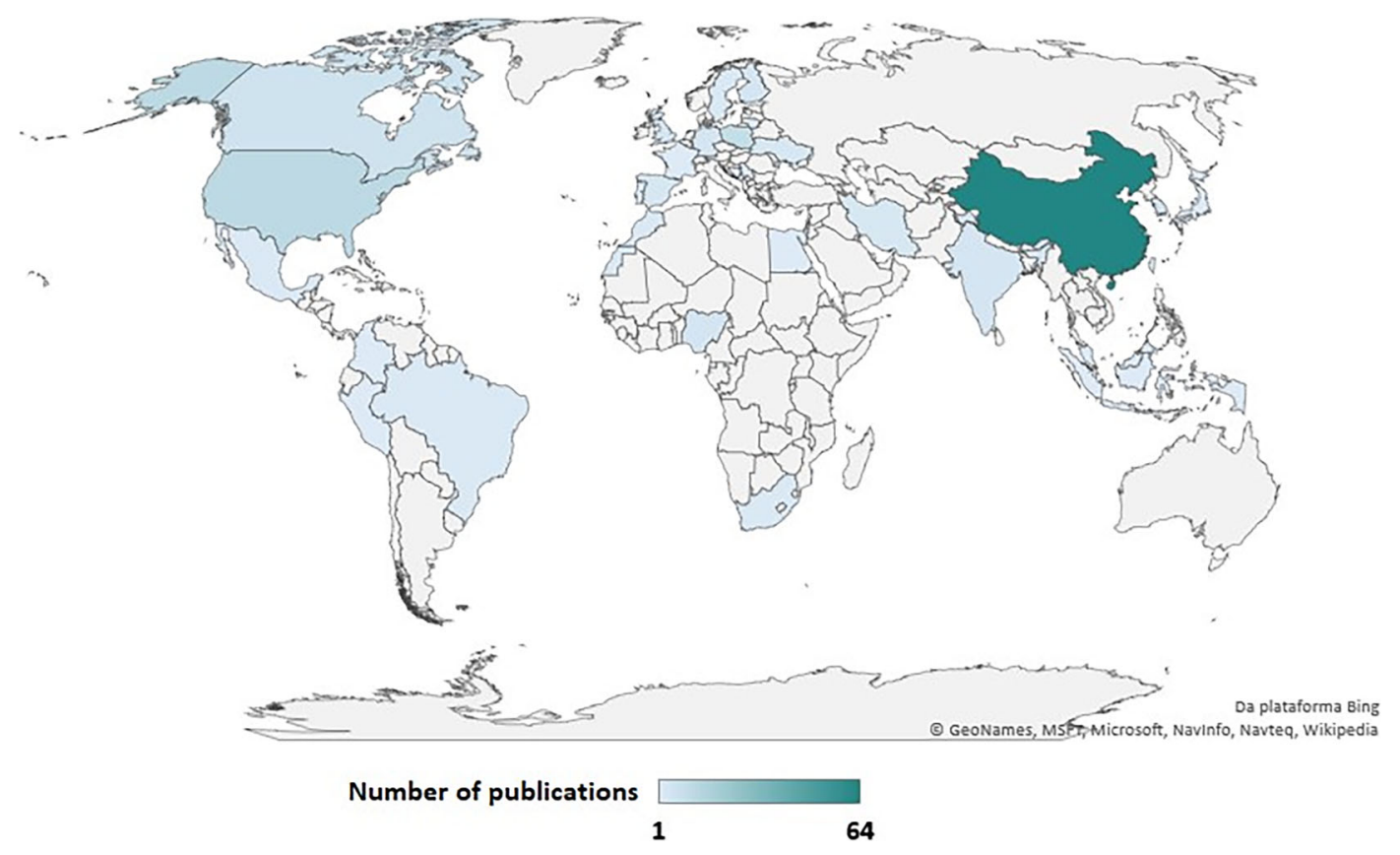

Fig. 3 Global geographical distribution of the literature on lignin research outputs from 2014 to early 2019 period 


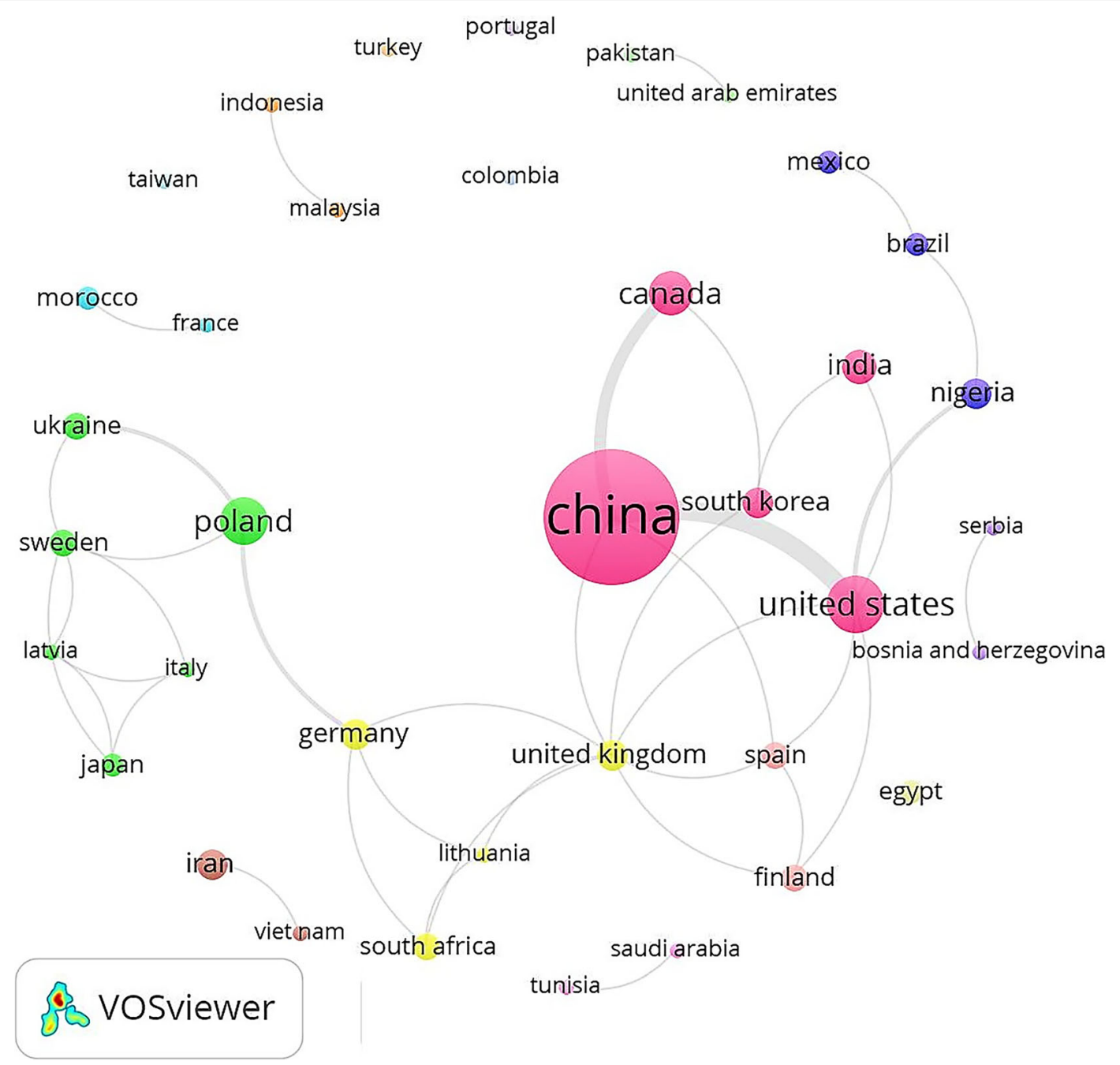

Fig. 4 Collaboration map among the top 10 most productive countries

were published in the years 2014 and 2015, with the citations varying from 107 to 46 . Since its publication, the study developed by Nair et al. (2014) was the most cited one (107 times). The authors discussed the development of chitosan-lignin composites for use as an adsorbent of metal ions and dyes in wastewater. The second most cited publication (60 times), presented by $\mathrm{Li}$ et al. (2015a), describes the production of a sphere with green porous lignin as a precursor in the removal of lead ions in aqueous media. In third place, with 57 citations, is the work developed by Klapiszewski et al. (2015), who obtained a functional silica/lignin hybrid material to be used as a novel adsorbent of nickel(II) and cadmium(II) ions in aqueous solutions.

In general, all the articles presented in Table 3 are original ones, focused on the use of lignin as an adsorbent, suggesting that this polymer has important adsorbent properties for heavy metal ions and dyespollutants commonly studied.

\subsection{Keywords Analysis}

The analysis of the keyword's occurrence extracted a total of 1514, of which 339 were defined by the authors of the documents and 1351 were indexed by Scopus in the publications. Through an in-depth analysis of these keywords, it is possible to understand the evolution of the research focus and development trends in the area of interest. It is important to note that a keyword can be part of the set of keywords indexed to each document by the database as well as those that were entered by the authors. For this 
Table 2 Institutions with the highest number of publications

\begin{tabular}{|c|c|c|c|c|}
\hline & Institution & Country & Number of publications & Percentage $(\%)$ \\
\hline 1 & Guangxi University & China & 15 & 11.5 \\
\hline 2 & South China University of Technology & China & 9 & 6.9 \\
\hline 3 & Ministry of Education China & China & 8 & 6.1 \\
\hline 4 & Politechnika Poznanska & Poland & 6 & 6.1 \\
\hline 5 & Maria Curie-Sklodowska University in Lublin & Poland & 5 & 3.8 \\
\hline 6 & Lakehead University & Canada & 5 & 3.8 \\
\hline 7 & Beijing Forestry University & China & 4 & 3.1 \\
\hline 8 & Northeast Forestry University & China & 4 & 3.1 \\
\hline 9 & Qilu University of Technology & China & 4 & 3.1 \\
\hline 10 & Fuzhou University & China & 4 & 3.1 \\
\hline
\end{tabular}

reason, the sum of such words does not account for those mentioned more than once, resulting in the amount shown. The study was directed to the words defined by the authors.

The list of the keywords most used by researchers in their work is shown in Table 4. The singular and plural forms of the words were associated to simplify the list.
The most common keywords were "lignin" and "adsorption" with a frequency of 66 and 59 in the publications, respectively. Both words are directly related to the set of keywords used for database searching. The word "adsorption" comprises most of the publications since several works among the 130 articles analyzed refer to this property of lignin. The words "heavy metal" and

Table 3 The top 10 highly cited papers published between 2014 and early 2019 period

\begin{tabular}{|c|c|c|c|c|}
\hline & Title & $\mathrm{TC}$ & Journal & Year \\
\hline 1 & $\begin{array}{l}\text { Development of novel chitosan-lignin composites for } \\
\text { adsorption of dyes and metal ions from wastewater (Nair et al. 2014) }\end{array}$ & 107 & Chemical Engineering Journal & 2014 \\
\hline 2 & $\begin{array}{l}\text { Fabrication of a green porous lignin-based sphere for } \\
\text { the removal of lead ions from aqueous media ( } \mathrm{Li} \text { et al. 2015a) }\end{array}$ & 60 & Journal of Hazardous Materials & 2015 \\
\hline 3 & $\begin{array}{l}\text { Silica conjugated with kraft lignin and its use as a novel } \\
\text { "green" sorbent for hazardous metal ions removal (Klapiszewski et al. 2015) }\end{array}$ & 57 & Chemical Engineering Journal & 2015 \\
\hline 4 & $\begin{array}{l}\text { Synthesis of porous lignin xanthate resin for } \mathrm{Pb}^{2+} \text { removal } \\
\text { from aqueous solution ( } \mathrm{Li} \text { et al. 2015b) }\end{array}$ & 55 & Chemical Engineering Journal & 2015 \\
\hline 5 & $\begin{array}{l}\text { Dithiocarbamate functionalized lignin for efficient removal } \\
\text { of metallic ions and the usage of the metal-loaded bio-sorbents } \\
\text { as potential free radical scavengers (Ge et al. 2014b) }\end{array}$ & 55 & Journal of Materials Chemistry A & 2014 \\
\hline 6 & $\begin{array}{l}\text { Modification of chitin with kraft lignin and development of } \\
\text { new biosorbents for removal of cadmium(II) and nickel(II) } \\
\text { ions (Wysokowski et al. 2014) }\end{array}$ & 54 & Marine Drugs & 2014 \\
\hline 7 & $\begin{array}{l}\text { A new, low-cost adsorbent: preparation, characterization, and } \\
\text { adsorption behavior of } \mathrm{Pb} \text { (II) and } \mathrm{Cu} \text { (II) (Huang et al. 2015) }\end{array}$ & 51 & Journal of Colloid and Interface Science & 2015 \\
\hline 8 & $\begin{array}{l}\text { Surface-functionalized porous lignin for fast and efficient lead removal } \\
\text { from aqueous solution ( } \mathrm{Li} \text { et al. 2015c) }\end{array}$ & 50 & ACS Applied Materials and Interfaces & 2015 \\
\hline 9 & $\begin{array}{l}\text { Adsorption of Procion Blue MX-R dye from aqueous solutions by } \\
\text { lignin chemically modified with aluminum and manganese } \\
\text { (Adebayo et al. 2014) }\end{array}$ & 46 & Journal of Hazardous Materials & 2014 \\
\hline 10 & $\begin{array}{l}\text { High-value utilization of lignin to synthesize } \mathrm{Ag} \text { nanoparticles with } \\
\text { detection capacity for } \mathrm{Hg}^{2+} \text { (Shen et al. 2014) }\end{array}$ & 46 & ACS Applied Materials and Interfaces & 2014 \\
\hline
\end{tabular}

$\mathrm{TC}$, total citations 
Table 4 The most used keywords

\begin{tabular}{lll}
\hline & Keyword & Frequency \\
\hline 1 & Lignin & 66 \\
2 & Adsorption & 59 \\
3 & Heavy metal & 17 \\
4 & Methylene blue & 8 \\
5 & Lead ion & 7 \\
6 & Wastewater & 7 \\
7 & Hydrogel & 7 \\
8 & Flocculant & 7 \\
9 & Kraft lignin & 6 \\
10 & Metal ion & 5
\end{tabular}

"metal ion" relate to the removal of heavy metals and their ions by lignin, just as the word "methylene blue" correlates to the removal of dyes from water. As noticed, these are the leading pollutants studied. Lignin removal of methylene blue dye is widely cited in the literature, as is the removal of lead ions. For this reason, the keyword "methylene blue" and "lead ion" are on this list. Furthermore, the word "kraft lignin" refers to the main type of lignin used in the analyzed works, while the words "flocculant" and "hydrogel" are related to how lignin is used often for the removal of polluting agents.

Before exporting data to VOSviewer, the words already mentioned in the plural and their synonyms were re-labeled. For example, "lignins" was replaced by "lignin," "adsorption process" was replaced by "adsorption," and "metallic ions" by "metal ion." Two minimum occurrences of keywords were defined in VOSviewer. The map with the network of the most used keywords within the established criteria is presented in Fig. 5.

The words "lignin" and "adsorption" have a larger node size, and the weight of edges between them is also higher compared to the other keywords (Fig. 5). This behavior indicates that in addition to the more frequent use of these two keywords, they are also used together. Besides that, the bigger weight of edges can be explained by a large amount of work describing the use of lignin as an adsorbent for the removal of pollutants. Besides that, these words also have a strong connection with the words "lead ion" and "heavy metal," indicating that a high proportion of articles is focused on the removal of such pollutants by lignin. The analysis of Fig. 5 also reveals other ways of using lignin that were found in the studies, for example, "biochar," "nanocomposite," and "biosorbent." These results are significant since it allows researchers to visualize the overview of research subject trends of scientific articles related to the proposed theme and also assists them in the development of new research.

\subsection{Publication Analysis and Hot Issues of Selected Literature}

Through the analysis of the publications, it was found that lignin was used in various ways in the works analyzed for application in the removal of pollutants in industrial effluents. As a result, the documents were divided into the following five categories: adsorbent, application as biosorbent, flocculant/coagulant, a raw material for hydrogel production, and others. This latter category includes articles that report the use of lignin as surfactant, membranes, in oxidative treatment, as well as aid in fungal oxidation and pipes cleaning. The chart of all five categories is shown in Fig. 6 .

The documents that fall into the adsorbent category describe the use of lignin as a raw material to produce activated carbon, foams, membranes, composites and nanocomposites, resins, nanomaterial, spheres and microspheres, lignin films and permeable barriers. Several of these works point out that the modification of lignin or manufacture of such materials, based on this natural polymer, increases the lignin adsorptive capacity improving the removal of chemical pollutants from industrial wastewater.

Regarding the types of chemical pollutants found in the literature, among the 130 articles evaluated, the highest proportion is related to heavy metal ions and dyes with percentages of 56.91 and $41.55 \%$, respectively. Lastly, there are also papers describing the use of lignin for both treatments of wastewater contaminated with pesticide (Hu and Chen 2015) and in the treatment of aqueous solutions contaminated with 4-nitrophenol (Martin-Martinez et al. 2017).

The following subtopics provide a detailed analysis of the content present in the selected literature regarding the use of lignin according to the categories listed in Fig. 6.

\subsubsection{Lignin as Adsorbent}

Several publications describe the application of crude or modified lignin as adsorbent. As is the case with the recent study by Li et al. (2018a), which, to increase the adsorption 


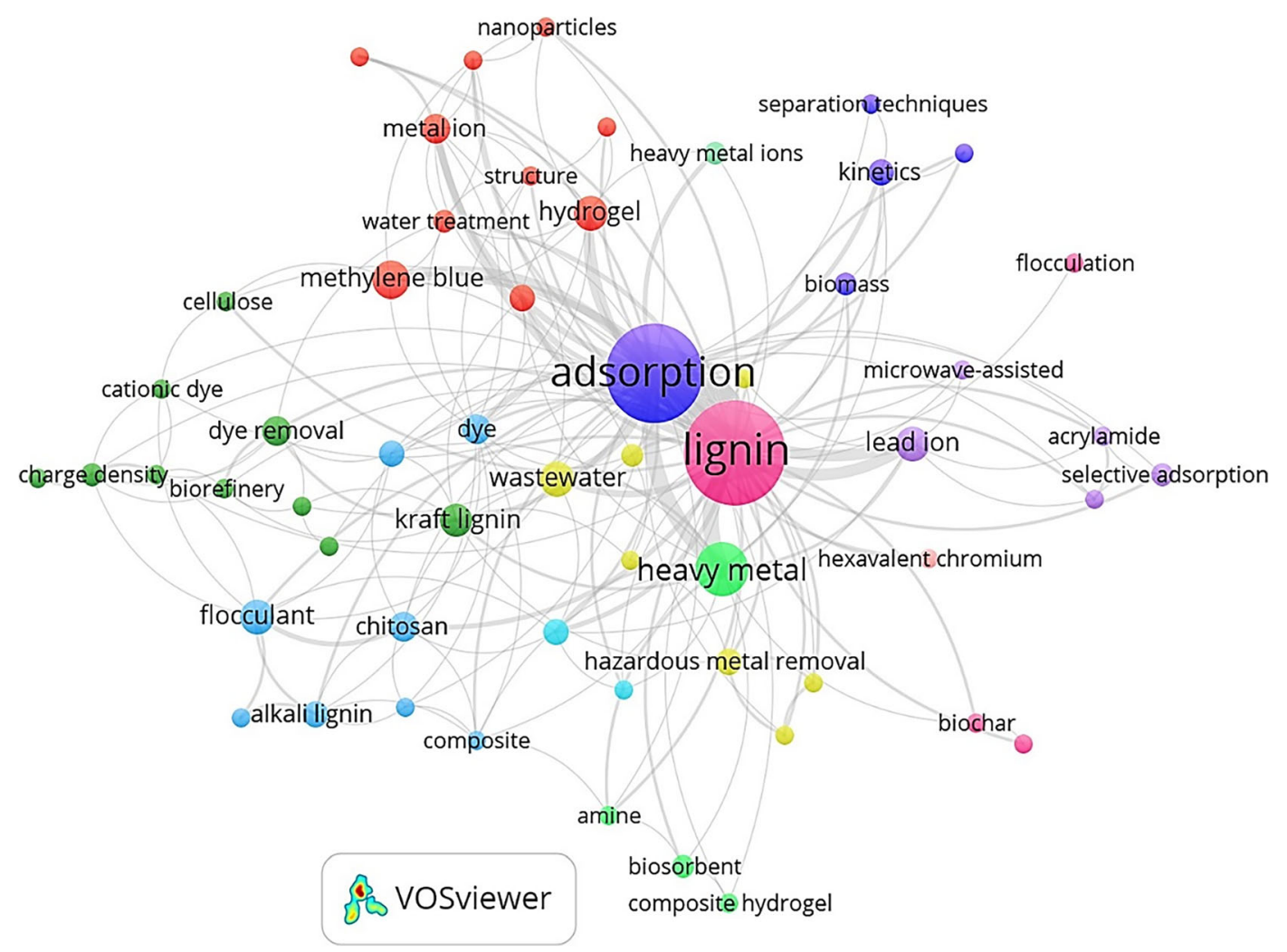

Fig. 5 Cluster map for the most used keywords based on the analysis of 130 publications indexed to Scopus

capacity of lead ions, synthesized a carboxymethylated lignin adsorbent by the microwave-assisted synthesis method, using alkaline lignin as a precursor. The adsorbent obtained presented adsorptive capacity values much higher than conventional adsorbents, such as commercial activated carbon, coconut-derived charcoal and zeolites, and other lignin-based adsorbents, being quantified at $302.3 \mathrm{mg} / \mathrm{g}$. The authors explained that the high adsorption capacity of carboxymethylated lignin could be attributed to a large number of adsorption sites resulting from the

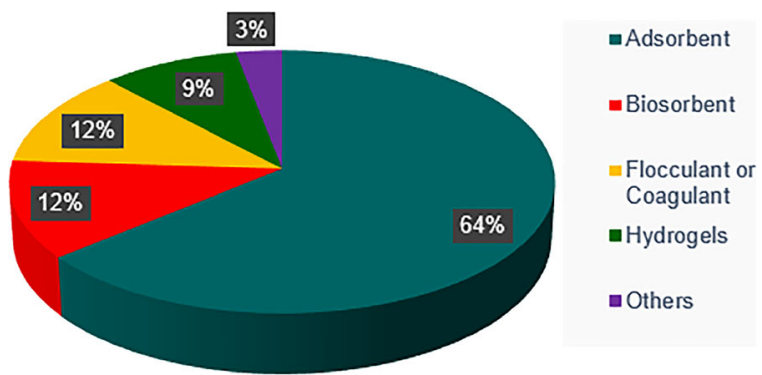

Fig. 6 Categories and their respective frequencies for the different lignin applications in the removal of pollutants in industrial effluents carboxyl groups that were incorporated into the lignin structure. Through microwave-assisted synthesis, the content of these groups was increased to $3.61 \mathrm{mmol} / \mathrm{g}$ in lignin. Additionally, the adsorption capacity of the studied material remained at $90 \%$ even after ten adsorptiondesorption cycles, which constitutes a potential alternative for the treatment of industrial effluents.

To improve lignin adsorption capacity for heavy metal ions (Cu(II) and $\mathrm{Pb}(\mathrm{II})$ ), Jin et al. (2018) synthesized an N-acetyl-L-cysteine (CFL) functionalized bamboo lignin-based adsorbent. The study found that due to the introduction of more adsorption sites, which are related to the cysteine chelating property, the maximum adsorption capacity for $\mathrm{Cu}$ (II) $(68.7 \mathrm{mg} / \mathrm{g})$ and $\mathrm{Pb}(\mathrm{II})$ ions $(55.5 \mathrm{mg} / \mathrm{g})$ was increased by 12.5 and 7.6 times, respectively, when compared to crude lignin. Also, the CFL adsorbent was more selective in the studied ions.

In a comparative study, Marouani et al. (2017) evaluated the adsorptive capacity of crude lignin, its derived charcoals (lignin char and lignin activated carbon), and commercial activated carbon in aqueous solutions of methylene blue and methyl orange dyes. The work inferred that crude lignin showed better results for 
methylene blue dye adsorption, while its derived charcoals showed good results for both dyes. However, lignin activated charcoal showed adsorption capacity comparable to commercial activated charcoal for methylene blue and higher for methyl orange, demonstrating the potential of active carbons from such polymer.

Lignin, oat, soy protein, sodium alginate, and chitosan nanofiber membranes were produced by Kolbasov et al. (2017). They evaluated lead adsorption capacity in solutions of such materials. According to the researchers, lignin-based nanofibers showed adsorption results comparable to conventional adsorbents, which demonstrates that lignin has excellent application potential since its cost is significantly lower than adsorbents used for the treatment of contaminated water.

The study developed by Kumari et al. (2016) reported the synthesis of new lignin-based polyurethane foam (LPUF) extracted from pine needles. The authors investigated the application of this foam to the removal of malachite green and methyl orange dyes in aqueous solutions. The obtained results have shown that LPUF proved to be an efficient material for removing dyes, with better results for the adsorption of cationic dye (malachite green), with maximum adsorption capacity for the analyzed pollutants of $80 \mathrm{mg} / \mathrm{g}$, besides having significant reuse, maintaining $60 \%$ efficiency even after 20 adsorption cycles.

A new dithiocarbamate functionalized organosolv lignin adsorbent (OLDTC) was obtained by Ge et al. (2016) from a microwave-assisted method for the removal of mercury ions in solution. The data showed that the saturation capacity of $\mathrm{Hg}(\mathrm{II})$, evaluated at $210 \mathrm{mg} / \mathrm{g}$, was 2.8 times higher than crude lignin and 16 times higher than polyacrylamide grafted cellulose adsorbents used for comparison. Additionally, the study demonstrated that functional groups were effectively introduced into the lignin structure due to the synthesis method used, which promoted a substantial increase in adsorbent adsorption capacity. This indicates that OLDTC can effectively adsorb the ions of mercury and other heavy metals.

Several other studies describe the use of lignin as a precursor material in the manufacture of nanoparticles (Li et al. 2018b), lignin films (Duan et al. 2018), spheres (Kwak et al. 2016), microspheres (Li et al. 2016), mesoporous material (Tang et al. 2016), resins (Li et al. 2015b) and permeable barriers (Kozyatnyk et al. 2014) for the treatment of effluents containing toxic chemical agents.

\subsubsection{Lignin as Biosorbent}

In the succeeding paragraphs are two of the works that use sorbents to remove dyes and heavy metals. Articles in this category highlight the simultaneous absorption and adsorption properties of lignin for the removal of contaminants, and therefore, these were not included in the adsorbent category.

In this perspective, Budnyak et al. (2018) investigated the sorption of methylene blue dye in aqueous solution. Silica hybrids and kraft lignins (from softwood) from the LignoBoost (LBL) and CleanFlowBlack (CFBL) processes were synthesized for this purpose. The results showed that the CFBL-based hybrid sorbent had a 30\% higher dye removal capacity than the LBLbased hybrid, a value measured at $60 \mathrm{mg} / \mathrm{g}$. Both materials extracted from 80 to $99 \%$ of the dye at $\mathrm{pH}$ in the range of 3 to 10 . The study also demonstrated that the surface regeneration capacity of the two evaluated sorbents exhibited high $\mathrm{HCl}$ values (up to $75 \%$ ) and ethanol (99\%), confirming its efficiency and applicability in industrial wastewater treatment processes.

$\mathrm{Xu}$ et al. (2017) synthesized a biosorbent from mesoporous lignin (MLBB) from rice straw through an $\mathrm{SO}_{3}$ micro-thermal-explosion process. This chemical modification of lignin provides a large number of sulfonic groups on the surface of lignin, which is very beneficial for removing heavy metal ions. The authors used $\mathrm{Pb}(\mathrm{II})$ as an ion model for the analysis. MLBB presented excellent ion capture performance, with a maximum capacity estimated at $952 \pm 31 \mathrm{mg} / \mathrm{g}$, a result attributed to the lignin mesoporous structure and the modification performed.

\subsubsection{Lignin as a Raw Material for Hydrogel Production}

Studies related to lignin as a precursor material to produce hydrogels report the following two mechanisms of pollutant separation: adsorption and absorption. Among the publications describing such characteristics of hydrogels, two will be described subsequently, each referring to a separation process. It should be noted that the publications in this category describe the use of lignin to produce hydrogels only and, therefore, they have not been included in the biosorbent category, which encompasses any sorbent material from lignin.

Domínguez-Robles et al. (2018) described the manufacture of high swelling lignin hydrogels for dye 
removal. The results indicated that these hydrogels had high efficiency in the removal of methylene blue dye from solutions. The percentages of removal ranged from 12 to $96 \%$ and depended directly on the negative surface charge of hydrogels as a result of the numerous carboxylic acid groups present in the samples. The study concluded that the hydrogels produced were able to absorb a higher amount of water and dye when compared to other hydrogels.

Yao et al. (2014) synthesized a modified lignin-based hydrogel referred to as bentonite/sodium lignosulfonate graft-polymerized with acrylamide and maleic anhydride (BLPAMA) and used it to remove metals from aqueous solution. The experiments showed that this hydrogel has a high adsorbing capacity for $\mathrm{Pb}^{2+}$ ions, reaching the maximum capacity at $\mathrm{pH}$ 5.0. The authors evaluated the competitive adsorption between $\mathrm{Pb}^{2+}$, $\mathrm{Cu}^{2+}, \mathrm{Cd}^{2+}$, and $\mathrm{Zn}^{2+}$ in quaternary metal solution. They concluded that the adsorbent presented high selectivity over $\mathrm{Pb}(\mathrm{II})$, inferring that this hydrogel can be used in effluents containing a high concentration of this ion.

\subsubsection{Lignin as a Flocculant or Coagulant Agent}

All documents reporting the use of lignin as a flocculant or a coagulant agent refer to the removal of effluent dyes. This outcome may be since both the coagulation and flocculation processes are preferably used for the treatment of dye-containing effluents because of their high efficiency, low cost, and energy-saving, once coagulants facilitate the aggregation of the dye particles to promote the neutralization of repulsive charges created between such particles (Wahlström et al. 2017).

In the study by Guo et al. (2018b), sulfonated hydroxypropyl lignin (SL) was produced by reacting lignin kraft with sodium 3-chloro-2-hydroxypropansulfonic acid to be used as a coagulant for cationic dyes. The efficiency of SL as a coagulant for removal of the basic blue 41 and ethyl violet dyes was higher than that of commercially produced lignosulfonate, reaching $93.05 \%$ removal and confirming the potential of the coagulant studied.

According to Cui et al. (2017), a ternary graft copolymer (chitosan-acrylamide lignin) was synthesized through microwave irradiation combined with a chemical-free radical initiator $\left(\mathrm{K}_{2} \mathrm{~S}_{2} \mathrm{O}_{8} / \mathrm{Na}_{2} \mathrm{~S}_{2} \mathrm{O}_{3}\right)$ for flocculant application. Flocculation performance was evaluated by the ability to remove acid black-172 synthetic dye. Data indicated that the color removal efficiency was $97.1 \%$ in dye wastewater, also pointing to a wide effective $\mathrm{pH}$ range (4 to 10 ) and an optimal removal even at various dosages of flocculant. The authors attributed these results to the various functional groups grafted during copolymerization, attesting to the potential of flocculant copolymer.

\subsubsection{Other Applications}

Applications of lignin that have been classified in this category involve the use of lignin as an amphoteric surfactant, like shown in the studies developed by Tian et al. (2014a) and Tian et al. (2014b), who synthesized dimethyl-butyl-sulfonated lignin ammonium chloride (DBSLAC) and dimethyl-acetoxy-(2-carboxymethyl ether)-lignin ammonium chloride (DALAC), respectively, from wheat straw alkali lignin. Both DBSLAC and DALAC adsorption performances were tested with a solution of copper ions as simulated wastewater. Their flocculation performance was investigated with acid black ATT (anionic dye) and methylene blue (cationic dye). These two different surfactants presented themselves as novel adsorbents for heavy metal ion and flocculants of dyes.

Han et al. (2014) evaluated the effect of lignin on the decolorization of four different azo dyes in vivo by the fungus Echinodontium taxodii. In the presence of lignin, a more efficient biodegradation was found since laccase (dominant enzyme) is induced by this polymer, obtaining $91.75 \%$ of decolorization for Remazol Brilliant Violet 5R (control 65.96\%), 76.89\% for Direct Red 5B (control 43.78\%), 43.44\% for Direct Black 38 (control $17.02 \%$ ), and $44.75 \%$ for Direct Black 22 (control $12.16 \%)$.

Huang et al. (2017) synthesized a biomass-based plumbing pipe cleaning agent (DHEL) from a ligninderived monomer (2-methoxy-4-propylphenol) for metal deposit removal of exhumed plastic pipe surfaces. With a dosage $\geq 5 \mathrm{mM}$ and neutral $\mathrm{pH}$, DHEL removed $\geq 95 \%$ of total metal deposits, showing higher favorability for $\mathrm{Cu}$ and $\mathrm{Zn}$ rather than $\mathrm{Fe}, \mathrm{Mn}$, and $\mathrm{Pb}$.

The study conducted by Huang et al. (2018) presented a renewable and inexpensive biopolymer synthesized from lignin (lig) interpenetrated into a polypyrrole (PPy) framework via an electropolymerization method. The $\mathrm{PPy} /$ lig composites formed were uniformly coated on a graphite felt (GF) to be used in electro-Fenton systems for oxygen reduction to $\mathrm{H}_{2} \mathrm{O}_{2}$. The oxidative treatment of wastewater performed by the PPy/lig-GF cathode achieved $92.55 \%$ decay of the initial AO7 (azo dye). 


\section{Conclusion}

In this review, the Scopus database was used to perform a complete bibliometric analysis of the scientific articles published during the 2014 to early 2019 period on the thematic of lignin applicability for the removal of chemical pollutants in effluents. The results of the analysis of the 130 evaluated documents evidenced the growing trend of research related to the use of lignin for the removal of chemical pollutants in effluents, having a large part of the articles focused on the areas of chemical engineering, chemistry, and environmental science. The most used language was English, accounting for about $90 \%$ of publications. China and the United States were the most productive countries in many studies; however, it was the United Kingdom countries that were leaders in international collaboration. Regarding the institutions, seven of the ten most productive ones are located in China, with Guangxi University being the most active. The fact that the United States does not appear in this ranking indicates the distribution of research conducted in the institutions of this country.

The top ten most cited papers are all original ones, and three of them were published in the Chemical Engineering Journal. Regarding the keywords used by the authors, "lignin" and "adsorption" are the most common among publications, indicating a large number of articles describing the use of lignin as an adsorbent for the removal of pollutants.

Studies have shown that lignin is a powerful alternative for replacing materials currently used in wastewater treatment, given its high availability, low cost, and biodegradability. Lignin has been reported as a raw material for the preparation of biomaterials, such as adsorbents, sorbents, flocculating agent, hydrogels, surfactants, as well as fungal oxidation aid, pipe cleaning, and cathode production material.

Acknowledgments The authors acknowledge financial assistance from the Brazilian research funding agencies such as CAPES (Coordination for the Improvement of Higher Education Personnel) under Finance Code 001, a Brazilian foundation within the Ministry of Education (MEC), CNPq (National Council for Scientific and Technological Development), a Brazilian foundation associated to the Ministry of Science and Technology (MCT), and FAPITEC/SE (the Foundation of Support to Research and Technological Innovation of the State of Sergipe).

\section{References}

Abejón, R. (2018). A bibliometric study of scientific publications regarding hemicellulose valorization during the 2000-2016 period: identification of alternatives and hot topics. ChemEngineering, 2.

Abejón, R., Pérez-Acebo, H., Clavijo L. (2018). Alternatives for chemical and biochemical lignin valorization: hot topics from a bibliometric analysis of the research published during the 2000-2016 period. Processes, 6.

Adebayo, M. A., Prola, L. D. T., Lima, E. C., Puchana-Rosero, M. J., Cataluña, R., Saucier, C., Umpierres, C. S., Vaghetti, J. C. P., Silva, L. G., \& Ruggiero, R. (2014). Adsorption of Procion Blue MX-R dye from aqueous solutions by lignin chemically modified with aluminium and manganese. Journal of Hazardous Materials, 268, 43-50.

Almeida, E., Assalin, M. R., Rosa, M. A., \& Durán, N. (2004). Tratamento de efluentes industriais por processos oxidativos na presença de ozônio. Química Nova, 27, 818-824.

Aniagor, C. O., \& Menkiti, M. C. (2018). Kinetics and mechanistic description of adsorptive uptake of crystal violet dye by lignified elephant grass complexed isolate. Journal of Environmental Chemical Engineering, 6, 2105-2118.

Bhatia, S. K., Jagtap, S. S., Bedekar, A. A., Bhatia, R. K., Patel, A. K., Pant, D., Rajesh Banu, J., Rao, C. V., Kim, Y., \& Yang, Y. (2020). Recent developments in pretreatment technologies on lignocellulosic biomass: effect of key parameters, technological improvements, and challenges. Bioresource Technology, 300, 122724

Budnyak, T. M., Aminzadeh, S., Pylypchuk, I. V., Sternik, D., Tertykh, V. A., Lindström, M. E., \& Sevastyanova, O. (2018). Methylene Blue dye sorption by hybrid materials from technical lignins. Journal of Environmental Chemical Engineering, 6, 4997-5007.

Cui, G., Wang, X., Xun, J., \& Lou, T. (2017). Microwave assisted synthesis and characterization of a ternary flocculant from chitosan, acrylamide and lignin. International Biodeterioration \& Biodegradation, 123, 269-275.

Demcak, S., Balintova, M., Hurakova, M., Frontasyeva, M. V., Zinicovscaia, I., \& Yushin, N. (2017). Utilization of poplar wood sawdust for heavy metals removal from model solutions. Nova Biotechnologica et Chimica, 16, 26-31.

Domínguez-Robles, J., Peresin, M. S., Tamminen, T., Rodríguez, A., Larrañeta, E., \& Jääskeläinen, A. (2018). Lignin-based hydrogels with "super-swelling" capacities for dye removal. International Journal of Biological Macromolecules, 115, 1249-1259.

Duan, Y., Freyburger, A., Kunz, W., \& Zollfrank, C. (2018). Lignin/chitin films and their adsorption characteristics for heavy metal ions. ACS Sustainable Chemistry \& Engineering, 6, 6965-6973.

Ennaert, T., Beeck, B. O., Vanneste, J., Smit, A. T., Huijgen, W. J. J., Vanhulsel, A., Jacobsa, P. A., \& Sels, B. F. (2016). The importance of pretreatment and feedstock purity in the reductive splitting of (ligno) cellulose by metal supported USY zeolite. Green Chemistry, 18, 2095-2105.

Food and Agriculture Organization of The United Nations, FAO. (2019). Pulp and paper capacities. http://www.fao.org/3 /ca5690t/CA5690T.pdf. Accessed 19 November 2019. 
Ge, Y., Li, Z., Kong, Y., Song, Q., \& Wang, K. (2014a). Heavy metal ions retention by bi-functionalized lignin: synthesis, applications, and adsorption mechanisms. Journal of Industrial and Engineering Chemistry, 20, 4429-4436.

Ge, Y., Xiao, D., Li, Z., \& Cui, X. (2014b). Dithiocarbamate functionalized lignin for efficient removal of metallic ions and the usage of the metal-loaded bio-sorbents as potential free radical scavengers. Journal of Materials Chemistry A, 2, 2136-2145.

Ge, Y., Xiao, D., Li, Z., \& Cui, X. (2016). Conversion of organosolv lignin into an efficient mercury ion adsorbent by a microwave-assisted method. Journal of the Taiwan Institute of Chemical Engineers, 63, 500-505.

Guo, K., Gao, B., Li, R., Wang, W., Yue, Q., \& Wang, Y. (2018a). Flocculation performance of lignin-based flocculant during reactive blue dye removal: comparison with commercial flocculants. Environmental Science and Pollution Research, 25, 2083-2095.

Guo, X., Zhang, S., \& Shan, X. (2008). Adsorption of metal ions on lignin. Journal of Hazardous Materials, 151, 134-142.

Guo, Y., Gao, W., \& Fatehi, P. (2018b). Hydroxypropyl sulfonated kraft lignin as a coagulant for cationic dye. Industrial Crops and Products, 124, 273-283.

Halysh, V., Sevastyanova, O., Riazanova, A. V., Pasalskiy, B., Budnyak, T., Lindström, M. E., \& Kartel, M. (2018). Walnut shells as a potential low-cost lignocellulosic sorbent for dyes and metal ions. Cellulose, 25, 4729-4742.

Han, Y., Shi, L., Meng, J., Yu, H., \& Zhang, X. (2014). Azo dye biodecolorization enhanced by Echinodontium taxodii cultured with lignin. PLoS One, 9, e109786.

Hu, S.-W., \& Chen, S. (2015). A multipurpose lignin-based adsorbent for metallic ions, nanoparticles and various organophosphate pesticides in hexane. Journal of the Chinese Chemical Society, 62, 875-888.

Huang, G., Wang, D., Ma, S., Chen, J., Jiang, L., \& Wang, P. (2015). A new, low-cost adsorbent: preparation, characterization, and adsorption behavior of $\mathrm{Pb}$ (II) and $\mathrm{Cu}(\mathrm{II})$. Journal of Colloid and Interface Science, 445, 294-302.

Huang, H., Han, C., Wang, G., \& Feng, C. (2018). Lignin combined with polypyrrole as a renewable cathode material for $\mathrm{H}_{2} \mathrm{O}_{2}$ generation and its application in the electro-Fenton process for azo dye removal. Electrochimica Acta, 259, 637-646.

Huang, X., Zhao, S., Abu-Omar, M., \& Whelton, A. J. (2017). Insitu cleaning of heavy metal contaminated plastic water pipes using a biomass derived ligand. Journal of Environmental Chemical Engineering, 5, 3622-3631.

Jin, C., Zhang, X., Xin, J., Liu, G., Chen, J., Wu, G., Liu, T., Zhang, J., \& Kong, Z. (2018). Thiol-ene synthesis of cysteine-functionalized lignin for the enhanced adsorption of $\mathrm{Cu}(\mathrm{II})$ and $\mathrm{Pb}(\mathrm{II})$. Industrial \& Engineering Chemistry Research, 57, 7872-7880.

Klapiszewski, Ł., Bartczak, P., Wysokowski, M., Jankowska, M., Kabat, K., \& Jesionowski, T. (2015). Silica conjugated with kraft lignin and its use as a novel 'green'sorbent for hazardous metal ions removal. Chemical Engineering Journal, 260, 684-693.

Kolbasov, A., Sinha-Ray, S., Yarin, A. L., \& Pourdeyhimi, B. (2017). Heavy metal adsorption on solution-blown biopolymer nanofiber membranes. Journal of Membrane Science, 530, 250-263.
Kozyatnyk, I., Haglund, P., Lövgren, L., Tysklind, M., Gustafsson, A., \& Törneman, N. (2014). Evaluation of barrier materials for removing pollutants from groundwater rich in natural organic matter. Water Science \& Technology, 70, 32-39.

Kumari, S., Chauhan, G. S., Monga, S., Kaushik, A., \& Ahn, J.-H. (2016). New lignin-based polyurethane foam for wastewater treatment. RSC Advances, 6, 77768-77776.

Kwak, H. W., Shin, M., Yun, H., Lee, K. H. (2016). Preparation of silk sericin/lignin blend beads for the removal of hexavalent chromium ions. International Journal of Molecular Sciences, 17.

Li, X., He, Y., Sui, H., He, L. (2018b). One-step fabrication of dual responsive lignin coated $\mathrm{Fe}_{3} \mathrm{O}_{4}$ nanoparticles for efficient removal of cationic and anionic dyes. Nanomaterials, 8.

Li, Y., Wu, M., Wang, B., Wu, Y., Ma, M., \& Zhang, X. (2016). Synthesis of magnetic lignin-based hollow microspheres: a highly adsorptive and reusable adsorbent derived from renewable resources. ACS Sustainable Chemistry \& Engineering, 4, 5523-5532.

Li, Y., Zhao, R., Pang, Y., Qiu, X., \& Yang, D. (2018a). Microwave-assisted synthesis of high carboxyl content of lignin for enhancing adsorption of lead. Colloids and Surfaces A: Physicochemical and Engineering Aspects, 553, 187-194.

Li, Z., Ge, Y., \& Wan, L. (2015a). Fabrication of a green porous lignin-based sphere for the removal of lead ions from aqueous media. Journal of Hazardous Materials, 285, 77-83.

Li, Z., Kong, Y., \& Ge, Y. (2015b). Synthesis of porous lignin xanthate resin for $\mathrm{Pb}^{2+}$ removal from aqueous solution. Chemical Engineering Journal, 270, 229-234.

Li, Z., Xiao, D., Ge, Y., \& Koehler, S. (2015c). Surfacefunctionalized porous lignin for fast and efficient lead removal from aqueous solution. ACS Applied Materials and Interfaces, 5, 15000-15009.

Mao, G., Huang, N., Chen, L., \& Wang, H. (2018). Research on biomass energy and environment from the past to the future: a bibliometric analysis. Science of the Total Environment, 635, 1081-1090.

Marouani, E. M., Fakir, L. E., Yakhaf, S. M. L., Hrech, N. E., Dahchour, A., Sebbahi, S., Hajjaji, S. E., \& Kifani-Sahban, F. (2017). Removal of textile dyes from aqueous solutions by lignin and its derivative charcoals: characterization, adsorption kinetics and isotherms. Desalination and Water Treatment, 81, 265-273.

Martin-Martinez, M., Barreiro, M. F. F., Silva, A. M. T., Figueiredo, J. L., Faria, J. L., \& Gomes, H. T. (2017). Lignin-based activated carbons as metal-free catalysts for the oxidative degradation of 4-nitrophenol in aqueous solution. Applied Catalysis B: Environmental, 219, 372-378.

Md Khudzari, J., Kurian, J., Tartakovsky, B., \& Raghavan, G. S. V. (2018). Bibliometric analysis of global research trends on microbial fuel cells using Scopus database. Biochemical Engineering Journal, 136, 51-60.

Michelin, M., Maria de, T. M. P. L., Ruzene, D. S., Silva, D. P., Vicente, A. A., Jorge, J. A., Terenzi, H. F., \& Teixeira, J. A. (2012). Xylanase and $\beta$-xylosidase production by Aspergillus ochraceus: new perspectives for the application of wheat straw autohydrolysis liquor. Applied Biochemistry and Biotechnology, 166, 336-347. 
Nair, V., Panigrahy, A., \& Vinu, R. (2014). Development of novel chitosan-lignin composites for adsorption of dyes and metal ions from wastewater. Chemical Engineering Journal, 254, 491-502.

Nasrullah, A., Bhat, A. H., Isa, M. H. (2016). Lignin: a sustainable biosorbent for heavy metal adsorption from wastewater, a review. AIP Conference Proceedings, 1787, 040001-1040001-7.

Ogunsile, B. O., \& Bamgboye, M. O. (2017). Biosorption of lead (II) onto soda lignin gels extracted from Nypa fruiticans. Journal of Environmental Chemical Engineering, 5, 27082717.

Pereira, G. C., \& Ebecken, N. F. F. (2009). Knowledge discovering for coastal waters classification. Expert Systems with Applications, 36, 8604-8609.

Qiu, X., Yu, J., Yang, D., Wang, J., Mo, W., \& Qian, Y. (2018). Whitening sulfonated alkali lignin via $\mathrm{H}_{2} \mathrm{O}_{2} / \mathrm{UV}$ radiation and its application as dye dispersant. ACS Sustainable Chemistry \& Engineering, 6, 1055-1060.

Ruas, T. L., \& Pereira, L. (2014). Como construir indicadores de Ciência, Tecnologia e Inovação usando Web of Science, Derwent World Patent Index, Bibexcel e Pajek? Perspectivas em Ciência da Informação, 19, 52-81.

Shen, Z., Luo, Y., Wang, Q., Wang, X., \& Sun, R. (2014). Highvalue utilization of lignin to synthesize $\mathrm{Ag}$ nanoparticles with detection capacity for $\mathrm{Hg}^{2+}$. ACS Applied Materials and Interfaces, 6, 16147-16155.

Shuhailath, K. A., Linsha, V., Kumar, S. N., Babitha, K. B., Peer Mohamed, A. A., \& Ananthakumar, S. (2016). Photoactive, antimicrobial $\mathrm{CeO}_{2}$ decorated $\mathrm{AlOOH} / \mathrm{PEI}$ hybrid nanocomposite: a multifunctional catalytic-sorbent for lignin and organic dye. RSC Advances, 6, 54357-54370.

Tang, Y., Zeng, Y., Hu, T., Zhou, Q., \& Peng, Y. (2016). Preparation of lignin sulfonate-based mesoporous materials for adsorbing malachite green from aqueous solution. Journal of Environmental Chemical Engineering, 4, 29002910.

Tian, J., Ren, S., Fang, G., \& Ai, Q. (2014a). Synthesis and property of dimethyl-butyl-sulfonated lignin ammonium chloride. Chemistry and Industry of Forest Products, 34, 42-50.

Tian, J., Ren, S., Fang, G., \& Ai, Q. (2014b). Preparation and performance of dimethyl-acetoxy-(2-carboxymethyl ether)lignin ammonium chloride amphoteric surfactant. Bioresources, 9, 6290-6303.

Tsay, M. (2008). A bibliometric analysis of hydrogen energy literature, 1965-2005. Scientometrics, 75, 421-438.
Wahlström, R., Kalliola, A., Heikkinen, J., Kyllönen, H., \& Tamminen, T. (2017). Lignin cationization with glycidyltrimethylammonium chloride aiming at water purification applications. Industrial Crops and Products, 104, 188-194.

Wang, B., Wen, J.-L., Sun, S.-L., Wang, H.-M., Wang, S.-F., Liu, Q.-Y., Charlton, A., \& Sun, R.-C. (2017). Chemosynthesis and structural characterization of a novel lignin-based biosorbent and its strong adsorption for $\mathrm{Pb}$ (II). Industrial Crops and Products, 108, 72-80.

Wysokowski, M., Klapiszewski, Ł., Moszyński, D., Bartczak, P., Szatkowski, T., Majchrzak, I., Siwińska-Stefańska, K., Bazhenov, V. V., \& Jesionowski, T. (2014). Modification of chitin with kraft lignin and development of new biosorbents for removal of cadmium(II) and nickel(II) ions. Marine Drugs, 10, 2245-2268.

Xu, F., Zhu, T.-T., Rao, Q.-Q., Shui, S.-W., Li, W.-W., He, H.-B., \& Yao, R.-S. (2017). Fabrication of mesoporous lignin-based biosorbent from rice straw and its application for heavymetal-ion removal. Journal of Environmental Sciences, 53, 132-140.

Yadav, B. R., \& Garg, A. (2016). Catalytic oxidation of pulping effluent by activated carbon-supported heterogeneous catalysts. Environmental Technology, 37, 1018-1025.

Yao, Q., Xie, J., Liu, J., Kang, H., \& Liu, Y. (2014). Adsorption of lead ions using a modified lignin hydrogel. Journal of Polymer Research, 21, 465.

Yao, Z., Wang, L., \& Qi, J. (2009). Biosorption of methylene blue from aqueous solution using a bioenergy forest waste: Xanthoceras sorbifolia seed coat. CLEAN-Soil, Air, Water, 37, 642-648.

Zhang, W., Han, Y., Haijiang, L., Ziwen, J., Lei, D., Xiaowei, K., Hu, Y., Aimin, L., \& Rongshi, C. (2011). Removal of dyes from aqueous solutions by straw based adsorbents: batch and column studies. Chemical Engineering Journal, 168, 11201127.

Zhao, Q. (2016). Lignification: flexibility, biosynthesis and regulation. Trends in Plant Science, 21, 713-721.

Zyoud, S. H., Fuchs-Hanusch, D., Zyoud, S. H., Al-Rawajfeh, A. E., \& Shaheen, H. Q. (2017). A bibliometric-based evaluation on environmental research in the Arab world. International journal of Environmental Science and Technology, 14, 689-706.

Publisher's Note Springer Nature remains neutral with regard to jurisdictional claims in published maps and institutional affiliations. 